\title{
The Public School System in Sindh: Empirical Insights
}

\section{Salman Asim*}

\begin{abstract}
This paper presents descriptive statistics on the government school education system in Sindh. The data are obtained from the latest administrative annual school census in Sindh (2011/12). The province's schooling system comprises 48,932 schools of which 47,000 are primary, middle, and elementary schools, giving Sindh one of the densest public schooling systems in the world with almost 1.8 schools for every 1,000 people in rural Sindh. The functional schooling capacity, however, is low, with less than 15 percent of these schools having at least two teachers and access to basic facilities such as toilets, drinking water, electricity, and boundary walls. Against this backdrop, we examine key trends in education outcomes using the Pakistan Living Standards and Measurement surveys for 2004/05 and 2010/11. We find that the net enrollment rates (NERs) at primary, middle, and secondary level in Sindh stagnated, at best, during 2007-11 after a sharp increase registered in 2006; this trend is similar to that of the rest of Pakistan. Gains in NER vary significantly across districts with some performing exceptionally better than others. Finally, we cross-validate these statistics using independent household-and school-level census data on 300 communities, collected as part of an ongoing impact evaluation study in three districts of rural Sindh.
\end{abstract}

Keywords: Patronage model, administrative data, PSLM, net enrollment rate, student achievement, public education, Sindh, Pakistan.

JEL classification: I21, I28, O20.

\section{Introduction}

Pakistan's economy experienced a remarkable turnaround in the early 2000s after reaching the verge of economic collapse in 1998. Its national GDP grew at an impressive average rate of 6 percent between 2000 and 2006. This cycle of episodic growth dissipated shortly as a result of

\footnotetext{
* World Bank. The author would like to thank Amit Dar, Dhushyanth Raju, Umbreen Arif, Naved Hamid, Masooma Habib, the Sindh government's Education and Literacy Department, and the Lahore School of Economics for their encouragement and assistance; and Mariam Adil, Surendra Agarwal, and Quynh Nguyen for useful feedback. The findings, interpretations, and conclusions expressed herein are the author's own and do not necessarily represent the views of the World Bank, its Board of Directors, or any of its member countries.
} 
unaddressed long-term structural constraints such as a low tax-to-GDP ratio, untargeted subsidies in the power sector, losses by state-owned enterprises, and dismal performance on human development indicators. These factors, accompanied by the global economic crisis, major floods in Sindh and Punjab, and overall deteriorating security conditions, have taken a toll on Pakistan's economy.

To steer the economy back onto a higher growth path and harness the potential of its vast human resource base for more robust and sustainable growth, the country must accelerate its progress on human development indicators. Currently, it ranks 163rd (out of 177) on the United Nations' index of education systems. Overall, the country's performance in school participation and completion is poor relative to its regional counterparts and to developing countries with a similar level of per capita income. That said, Pakistan did witness improvements in school participation rates between 2004 and 2007, but this promising trajectory of growth in human development was reversed with the slowdown in economic activity (see Figure 1).

Figure 1: Economic and education progress in Pakistan (1999-2010)

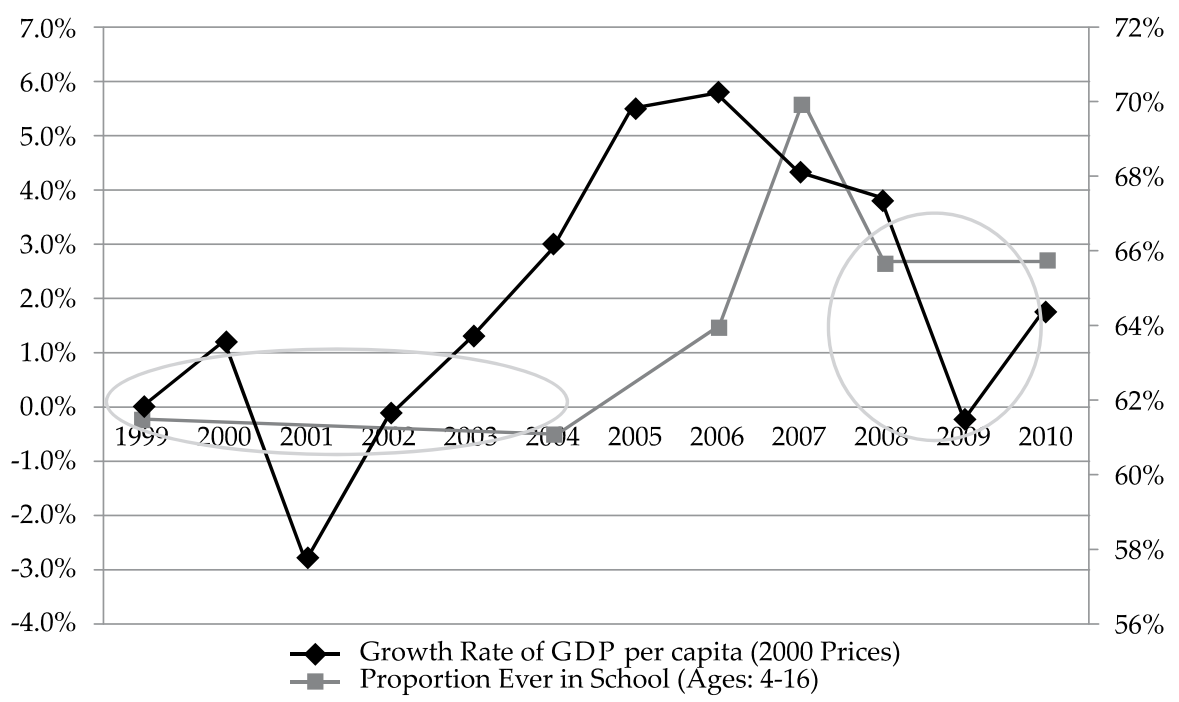

The province of Sindh is no exception as far as the poor state of education in the country is concerned. With a population of approximately 42 million people - roughly one quarter of the country's total populationthe province has a net enrollment rate (NER) of 62 percent, which drops to 54 percent in rural areas. The proportion of uneducated youth (aged 15-19) in Sindh is 31 percent compared to 27 percent nationally, which, in turn, is 
almost double the proportion of uneducated youth in any economy with a comparable per capita income. Overall, the percentage of uneducated females in Pakistan is disproportionately larger than that of males, but as illustrated in Figure 2, the shrinking of the uneducated population in the last decade can be attributed mainly to higher school participation rates among females compared to males. Sindh follows similar patterns.

Figure 2: Population pyramid by gender, age, and education levels

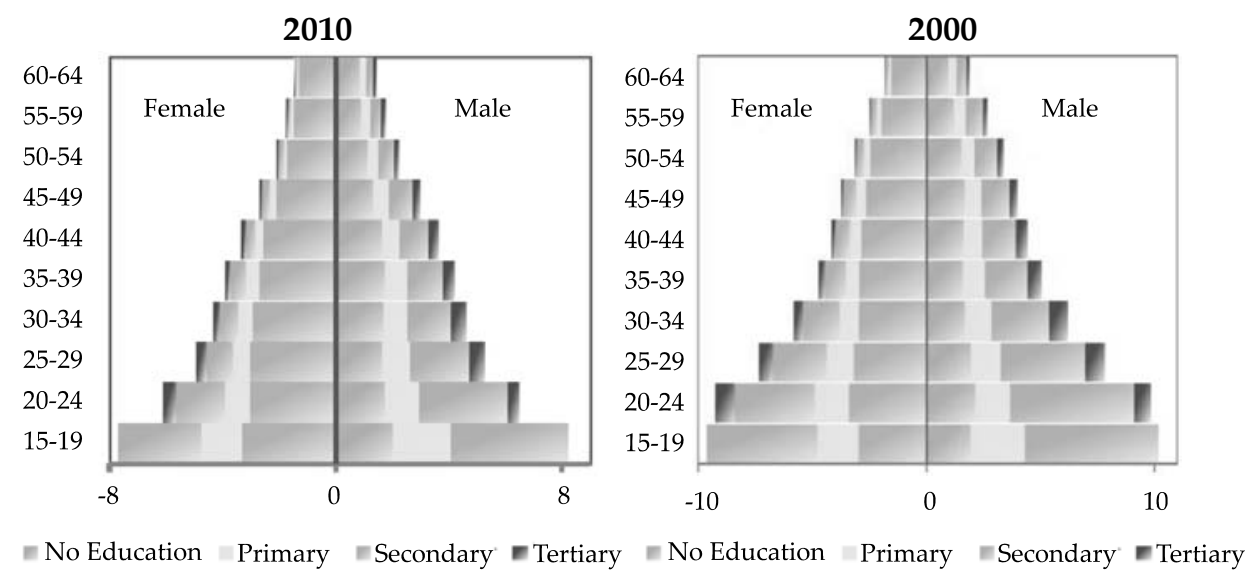

Source: EdStats (2010).

In March 2013, the legislative assembly enacted the Sindh Right of Children to Free and Compulsory Education Bill, which makes education mandatory for all children aged 5-16 years. The extent to which the Sindh government will be able to translate this act into access to quality education for all will depend on how the government addresses long-term structural challenges to the system that could derail even well-intentioned reforms. To inform this discussion, we present key trends, comparisons over time, and clues in the data that strip down the province's complex education landscape into simplified numbers. Section 2 provides a snapshot of Sindh's school education system, Section 3 examines key trends in education performance indicators over time, Section 4 reports robustness checks on the statistics presented in this paper, and Section 5 concludes our assessment.

\section{Sindh's Education System}

There are 48,932 government schools in Sindh, of which 43,027 are functional and 42,620 have at least one teacher and positive enrollments. About 38,471 are primary schools, 2,252 are middle/elementary schools, and 1,897 are secondary/higher secondary schools. Roughly, 3.65 million 
students are enrolled in these schools and are taught by a total of 147,945 working teachers. Of these, 141,718 are government teachers comprising 100,858 male teachers and 47,087 female teachers.

These numbers reveal that Sindh has one of the densest schooling systems in the world, with 47,000 government schools serving elementary grades in the province. To illustrate the sheer size of the system, we compare the number of elementary schools in the US per 1,000 people with those in Sindh and rural Sindh. The comparison is for illustrative purposes only and does not control for differences in the spatial distribution of population in Sindh and states in the US (Figure 3).

Figure 3: Schools per 1,000 people

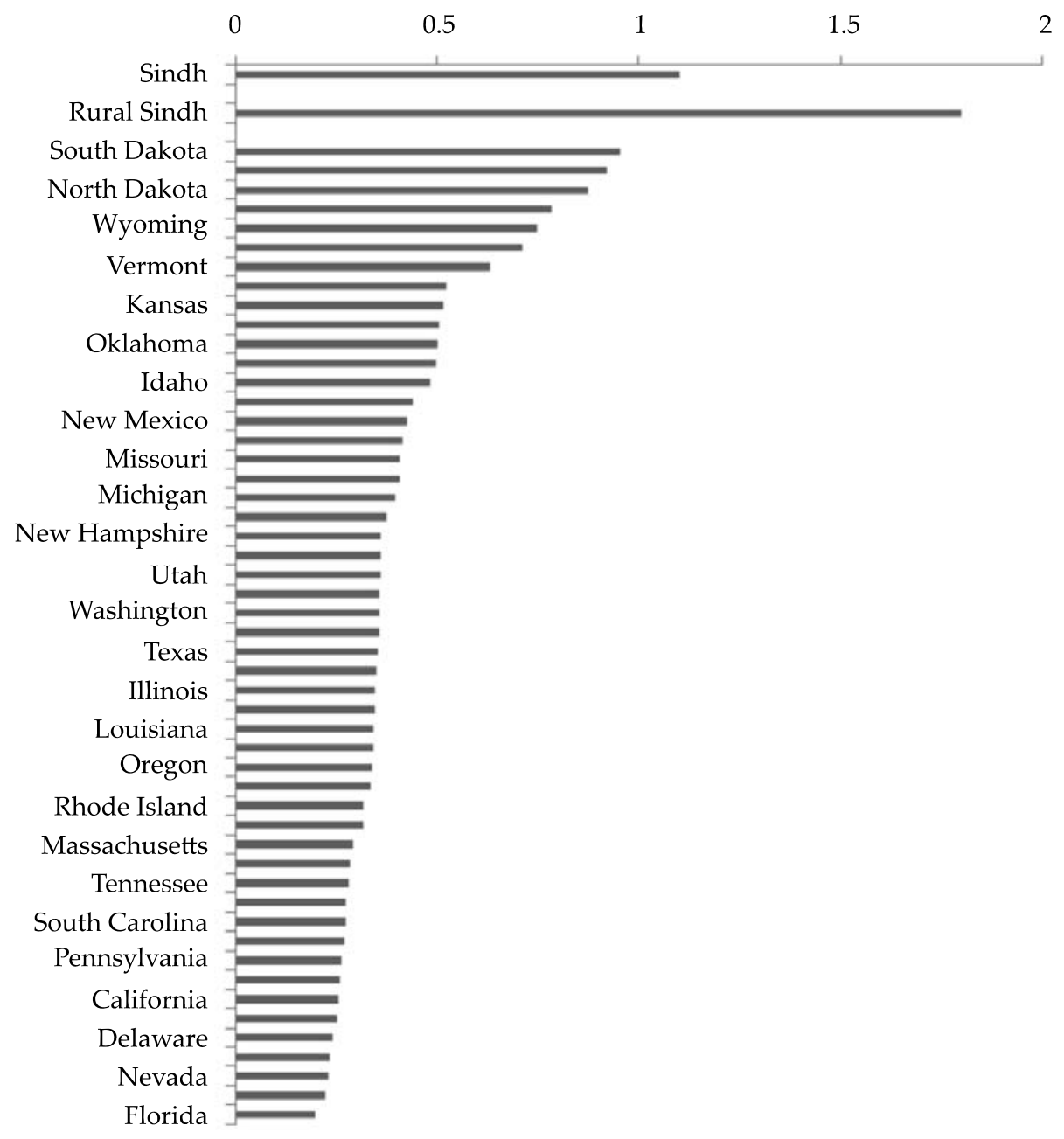


A quick look at the median school enrollments in Sindh for primary, middle, and elementary schools detracts from the optimistic thought that Sindh surpasses the US in managing to create a dense web of government schools. The median school intake for elementary schools in Sindh is only 40 students. As Figure 4 shows, a significant proportion of these schools (10-15 percent) are nonfunctional (zero enrollment) while others have very low enrollment rates. This is symptomatic of the Sindh's patronage model of politics where schools were created to serve targeted constituencies. Under this model, schools were constructed primarily to fulfill the objective of job creation (to buy votes) and to accumulate rents associated with the construction of schools and placement of teachers (Cheema \& Mohmand, 2006; Keefer, Narayan, \& Vishwanath, 2003; Gazdar 2000).

Figure 4: School enrollment density function

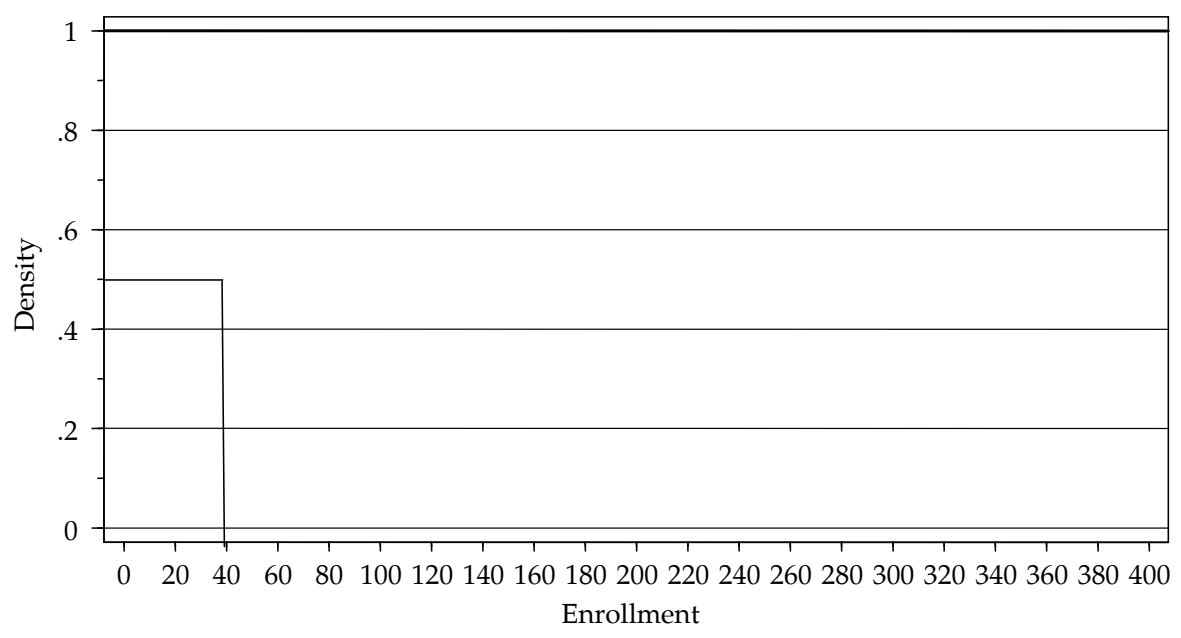

We find evidence of patronage-based politics once again when we look at the placement of teachers in schools. Overall, the student-teacher ratio (STR) in elementary and secondary schools in Sindh is 30. This average is comparable with or even better than that of countries with similar levels of per capita income and implies that Pakistan is on track to achieving the Millennium Development Goals. However, it masks huge regional and intra-district variations: Karachi city and Hyderabad (urban districts) have STRs of 20 compared to Jacobabad, Tharparkar, and Kambhar Shahdadkot where the average is more than 40 (Figure 5). Even within districts, schools located in urban centers have significantly higher STRs than rural schools. These patterns clearly suggest political patronage at work where teachers wielding adequate political clout are placed in schools where there is the least need. 
Figure 5: District and intra-district variations in STRs
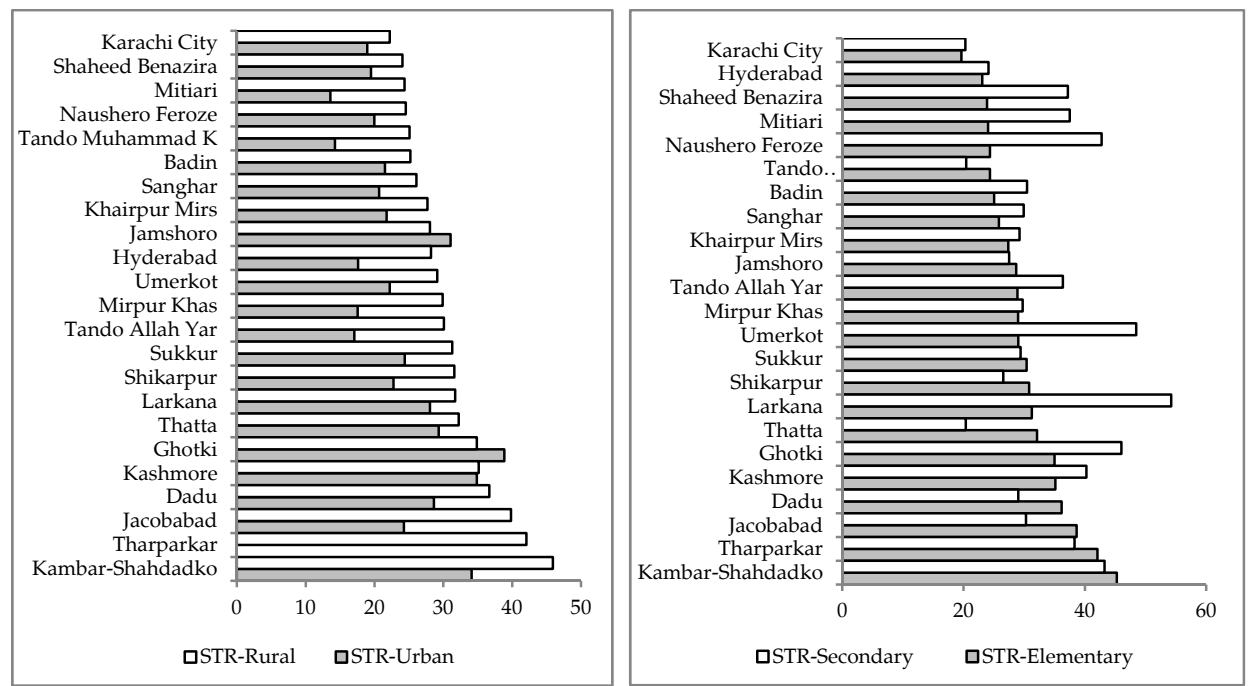

Having established the heterogeneity of the schooling system in Sindh, we now take a more nuanced look at the data to present key insights intended to inform education policy and management in the province. The focus is on government primary, middle, and elementary schools, which constitute more than 96 percent of the total schools Sindh, of which almost 90 percent are rural. We carefully analyze the data to identify "functioning schools" that meet the minimum definition of what a school is expected to be. We start with a base of 42,114 elementary schools in rural Sindh; 6,082 of these were either found closed for a period of more than six months in the annual school census data, had no teacher assigned to them or reported zero enrollment. Excluding these, we are left with a total of 36,082 schools with a teacher distribution depicted in Figure 6 below.

Figure 6: Teacher distribution in functional rural schools

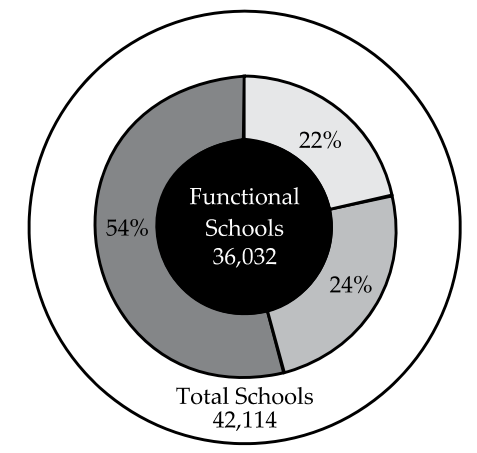

$\square$ More than 2 teachers $\square 2$ teachers $\quad \square 1$ teacher 
About 54 percent of these schools are one-teacher schools. Given the political economy assessment above, we need to differentiate between resource-constrained schools in the province ("needy") and schools that feed the political elite ("feedy"). Teacher management policies in the province must be sensitive to the distinction between "feedy" and "needy" schools in order to steer the education system back on track and away from the distortions created by deep-seated vested interests.

Specifically, we propose that any school in a given district that falls in the bottom quintile of STRs in that district is classified as "feedy"1_ these schools should be on policymakers' "negative list" with the intention of expunging them from the system in due course. Hence, any form of additional school inputs (teachers, school facilities, grants) should not be channeled to these schools, or we risk feeding the world of politics, interests, and power. There are a total of 4,038 "feedy" schools in the province with a mean STR (across districts) of 15.9 (Figure 7). Total enrollment in these schools is less than 65,000 and simple internal efficiency estimates are sufficient to write them off.

\section{Figure 7: Mean STRs in "feedy" schools}

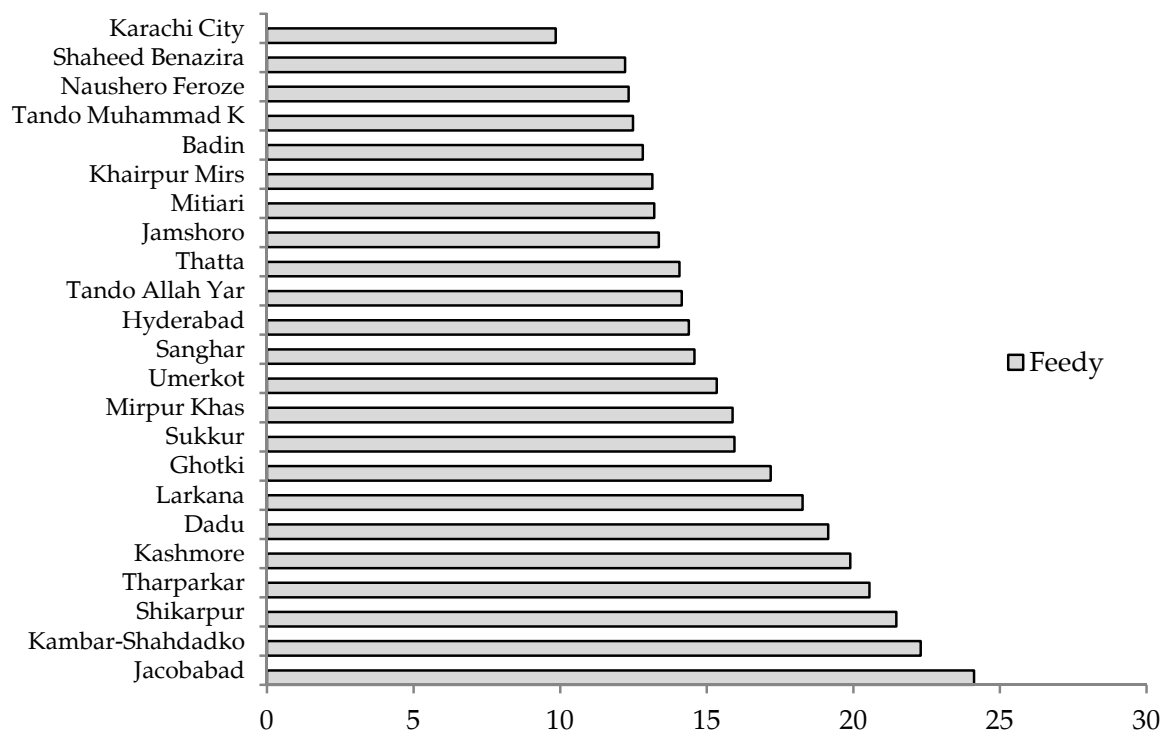

With these simple clues from the data, we have reduced the schooling system in rural Sindh from more than 42,000 to less than 32,000

\footnotetext{
${ }^{1}$ The relationship between school size and performance (earlier in the context of Sanghar district) is discussed in detail in Gazdar (2000).
} 
schools. Going further, we use a refined definition of school functioning that extends beyond students and teachers. We now look at the distribution of basic facilities in functional rural schools, such as toilets, drinking water, electricity, and boundary walls (see Figure 8).

\section{Figure 8: School facilities in functional rural schools}

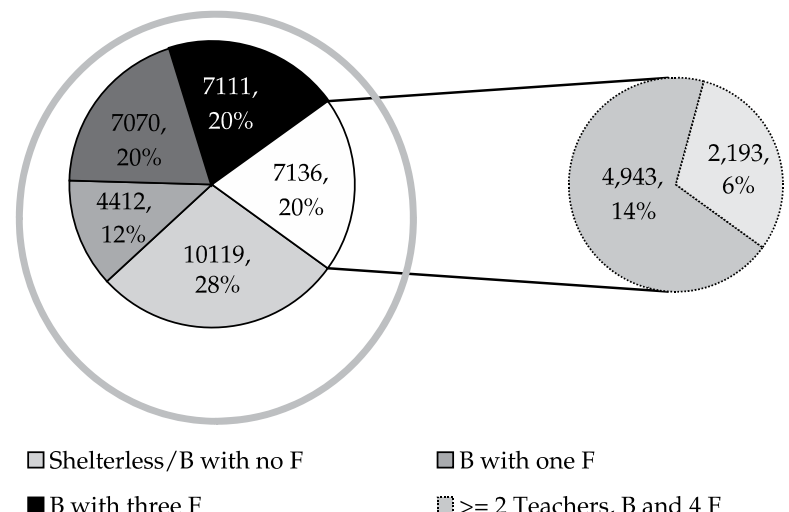

$\square$ B with two F

$$
\text { a with three } \mathrm{F}
$$

$$
\text { i... }>2 \text { Teachers, } \mathrm{B} \text { and } 4 \mathrm{~F}
$$

1 Teacher, $\mathrm{B}$ and $4 \mathrm{~F}$

As the figure shows, 28 percent of functional rural schools in the province either lack a school building or have one with none of the four basic facilities for students; 70 percent are one-teacher schools. In this massive public education outlay in Sindh, the school functioning capacity remains limited to less than 5,000 schools-schools with two or more teachers and access to the four basic facilities. To further our political economy analysis of "needy" versus "feedy" schools, we use a simple matching algorithm to identify functioning schools that share the infrastructure characteristics of closed schools. There are 5,633 at-risk schools that, similar to closed schools, lack physical infrastructure (access to the four basic facilities). The median STR for these schools is 26 with a mean of 31, indicating a fat right tail.

To remain conservative, we add to the list of "feedy" schools only those that have a below-median STR with virtually the same school infrastructure characteristics as closed schools. These calculations suggest that another 1,880 schools could be categorized as "feedy," thus reducing the elementary schooling system in Sindh to 30,000 potentially functioning schools. The enrollment cost of excluding these additional 5,633 schools in the province is 124,000 students. The total reported elementary enrollment in rural Sindh falls from 2.04 million to 2.03 million 
With these remaining 30,000 schools in rural Sindh, the province still retains its undisputed top position on the school density chart. There will still be some "feedy" schools camouflaged in this reduced set of 30,000, but they have characteristics similar to functioning schools in the province, and we cannot refine the categorization based on observed school covariates. Evidence of such schools is indicated by the skewed distribution of enrollment shares for these 30,000 schools: 1.5 million children are enrolled in 15,000 of these schools with only 0.5 million in the remaining schools (Figure 9).

Figure 9: School size heterogeneity in functional schools

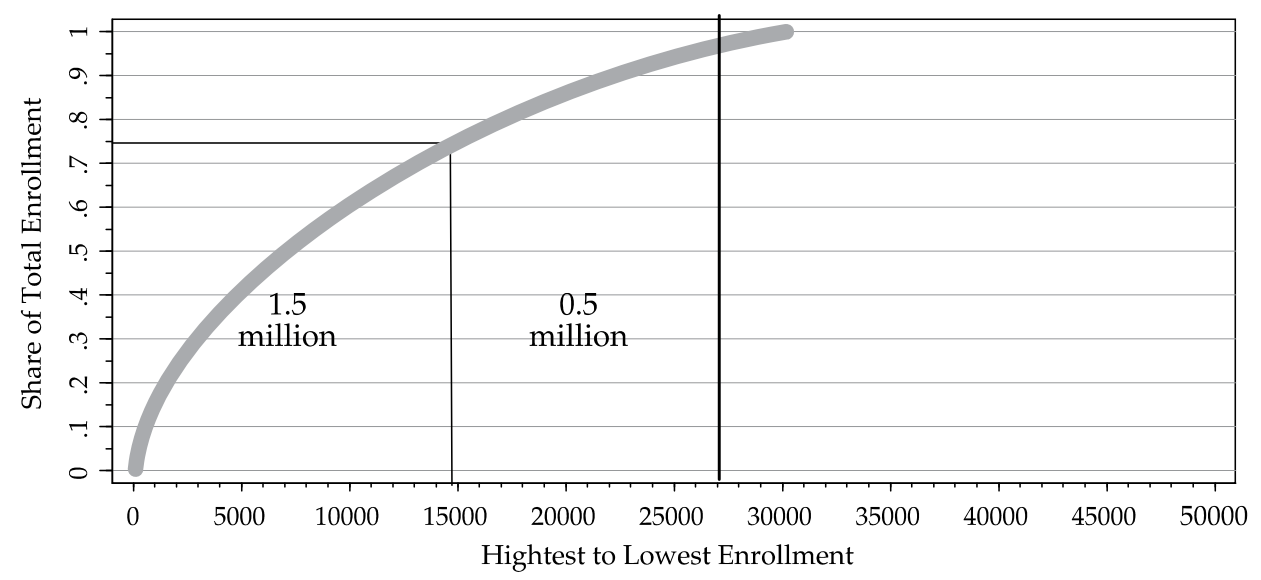

\section{Education Indicators in Rural Sindh}

Against the backdrop of this large proportion of nonfunctional schools in Sindh, we now examine whether the deadweight they create overburdens the education system and stalls the progress of key outcome indicators.

Sindh's performance in education outcomes is qualitatively similar to that of the other provinces. In 2011, the NERs at the primary (ages 6-10, grades 1-5), middle (ages 11-13, grades 6-8), and high school (ages 14-15, grades 9-10) levels in Sindh were 62, 36, and 23 percent, respectively. Growth in school participation at all three levels has been slow (i.e., singledigit growth) over the period 2005-11. The upward trajectory in NERs witnessed at all levels during 2004-07 was reversed in 2008, with larger participation shortfalls registered for children from poor households and girls in rural areas. 
Figure 10: Trends in NERs: primary, middle, and secondary levels
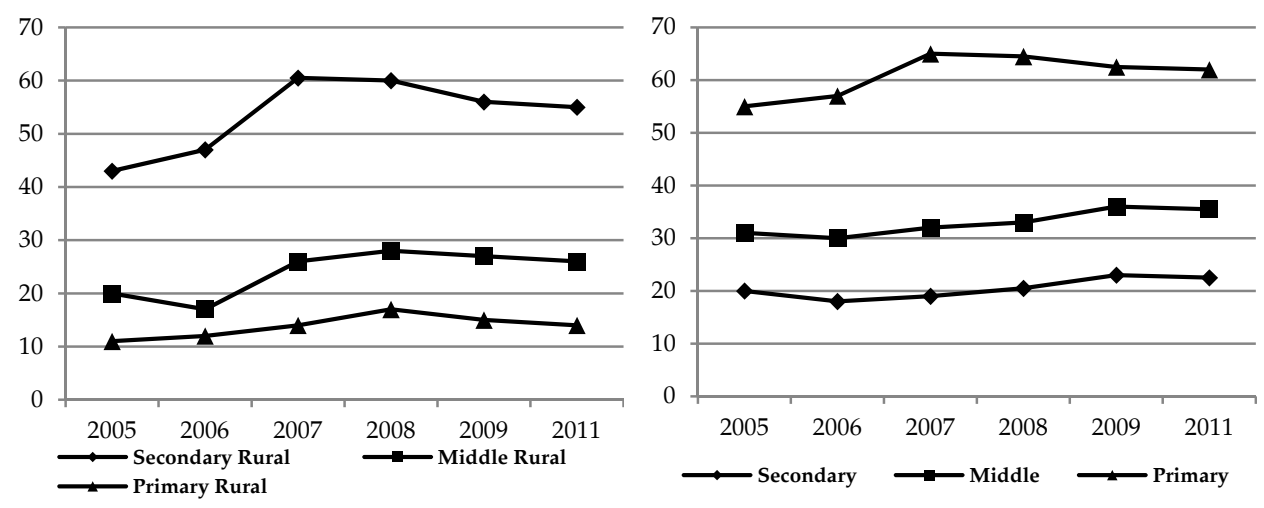

Likewise, student achievement in Sindh is low, with students performing well below their grade-level competencies in independent tests (mathematics, English, and Sindhi) administered in 2012.2 The tests were administered to 4,863 Grade 4 and Grade 5 students in a districtrepresentative sample. On average, students attempted 74 percent of the test items in mathematics and 70 percent of the test items in English; they achieved a mean score of 12.01 for mathematics and 10.82 for English out of 25 tested items in both subjects. Taking a specific question, less than 60 percent could answer a Grade 2-level question on adding two two-digit numbers.

With the exception of one sample district, the performance of the other seven rural districts was more or less similar in terms of mean student achievement (Figure 11). Even if we disaggregate the scores across gender, we do not see much difference in learning levels between girls and boys. Of the total sample, 1,627 were girls and 3,158 were boys; girls performed slightly better than boys in both mathematics and English.

\footnotetext{
2 These assessments were conducted as part of the baseline surveys for an ongoing information awareness campaign to build demand-side accountability pressures to improve school management in Sindh.
} 
Figure 11: Student achievment in math and English tests, 2012

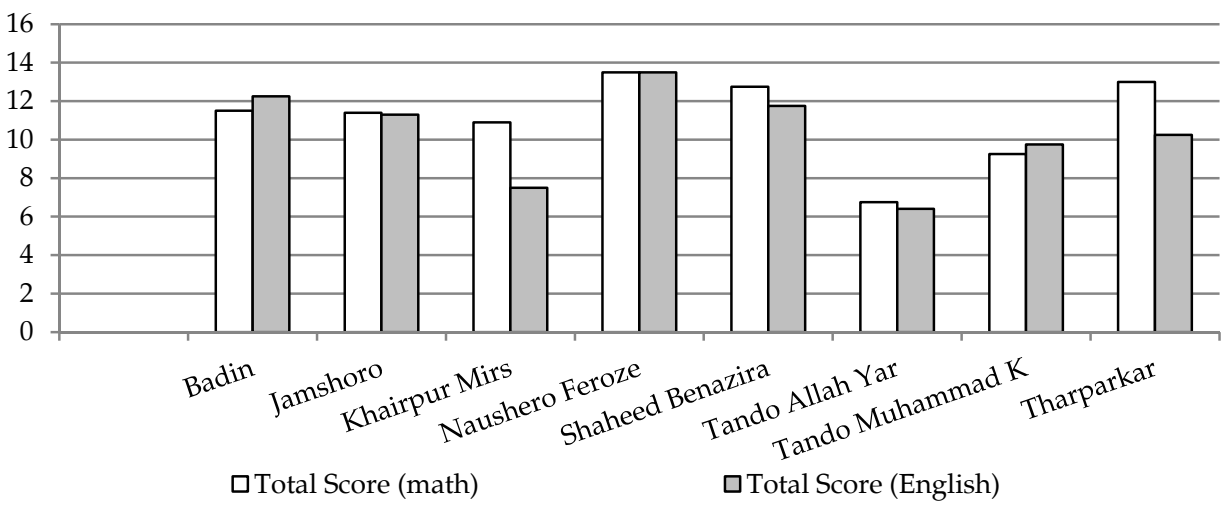

There also appear to be systematic differences in mean test performance across age groups. Age is discretized based on children younger than the official age for completing primary school (10 years or below, which is also the median age of the sample) and those older than 10 years (who should have completed Grade 5 by now). Across the tested grades, younger students have higher mean test scores than those older than the median age in the sample.

Table 1: Test scores across age groups

\begin{tabular}{lcc}
\hline Age & Total score (math) & Total score (English) \\
\hline$>10$ years & 11.61519 & 10.28518 \\
$<=10$ years & 12.24337 & 11.14396 \\
Total & 12.00995 & 10.82485 \\
\hline
\end{tabular}

Next, we take a closer look at primary NERs in rural area to examine any district-level heterogeneity in school participation rates across districts over time (Figure 12). There are significant differences in school participation rates across the province's 23 districts. However, barring Karachi and Hyderabad where private education predominates, districts have far more similar rates of government school participation. The decision to carve four new districts out of Larkana, Dadu, Khairpur, and Jacobabad to reduce the administrative burden seems to have worked, with significant gains in NERs for both the parent and bifurcated districts. ${ }^{3}$

\footnotetext{
${ }^{3}$ Districts established in 2004 are re-merged with their parent district to compare performance over time. We have assumed that the primary sampling units for the PSLM 2004/05 and 2010/11 were by no means affected by the change in administrative district boundaries.
} 


\section{Figure 12: Over-time comparison of primary NERs (rural)}

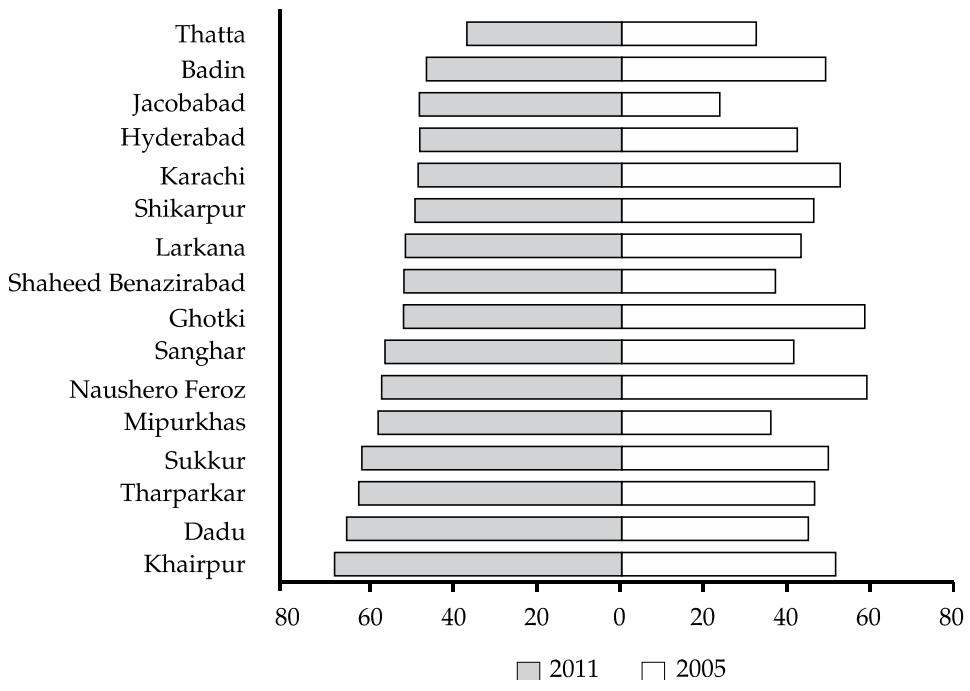

School participation rates in rural areas have improved in most districts, although these gains have been offset by worryingly negative and stagnant growth trajectories in others. Unsurprisingly, Thatta, the district with the highest concentration of "feedy" schools, has the lowest primary NER. Ghotki and Badin in rural Sindh registered negative NER growth over the six-year period. Mirpurkhas, Jacobabad, and Dadu, however, exhibited growth rates upward of 20 percent in the same period. These developments mean that regional disparities in educational attainment are on the rise in Sindh, and targeted policies must be adopted to deal with districts that are lagging behind in basic education outcomes.

School participation rates at the primary level in each district are based on the proportion of children (aged 6-10) attending Grades 1-5. Given the small number of sample observations for the relevant age group for each district, we must cross-validate these statistics to obtain a degree of confidence for the trends reported here.

\section{Robustness Checks}

To cross-validate the descriptive statistics reported in this paper, we use household- and school-level census data collected for 300 villages in three districts of rural Sindh-Matiari, Mirpurkhas, and Sanghar. ${ }^{4}$ Table 2

\footnotetext{
${ }^{4}$ Household listings and school censuses were conducted in 2012 across 300 randomly selected villages in three districts of Sindh as part of the ongoing impact evaluation work for the information awareness campaign in Sindh.
} 
below gives the school participation rates for school-age children (aged 516) in these districts, compared with those estimated in the PSLM survey for 2010/11. Population estimates obtained from the census listing of households in Sanghar and Matiari are very close to those reported in the household survey data. However, the unexpected gains in the NER for Mirpurkhas are inconsistent with the estimate we obtained from our study sample; sampling errors in the PSLM data may have led to this deviation from the population mean.

Table 2: Participation rates in three districts (children aged 5-16)

\begin{tabular}{lcc}
\hline & \multicolumn{2}{c}{ Participation rates } \\
\cline { 2 - 3 } & PSLM (2011) & Census (2012) \\
\hline Sanghar & $47.8 \%$ & $50.6 \%$ \\
Matiari & $42.9 \%$ & $42.9 \%$ \\
Mirpurkhas & $48.8 \%$ & $28.7 \%$ \\
\hline
\end{tabular}

The census data was collected for 300 randomly selected villages in Sanghar, Mirpurkhas, and Matiari. A total of 181,061 households were listed in these villages, and 1,727 schools were mapped. Out of these, 1,644 are public primary schools, 19 are middle schools, and 21 are secondary schools. In sharp contrast to Punjab, the private sector is virtually absent in rural Sindh, with only 14 private schools captured in the village-level census. These numbers can be generalized for the entire province as household survey data from 2011 indicate that private school participation for children aged 6-10 in rural Sindh is less than 1 percent (Figure 13).

Figure 13: Level and type distribution of schools

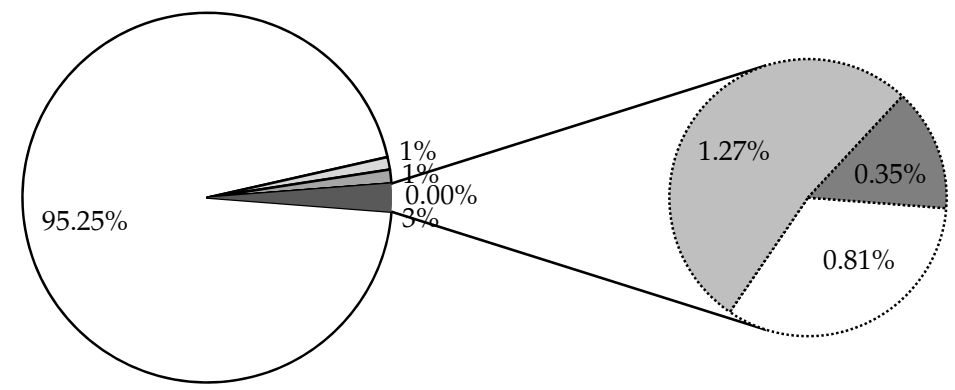

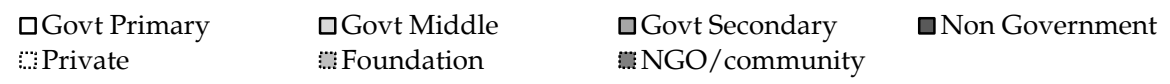


We limit our analysis to 1,626 government primary schools that were asked to fill out a basic census information sheet. A series of random visits revealed 880 of these schools to be functional (in session). We have categorized the closed schools as those that have been closed for (i) a year or more, (ii) a month or more, or (iii) less than 30 days on the day they were visited. Roughly 24 percent fall in the first category (closed for a year or more) It is reassuring to note that the number of "feedy" schools estimated in Section 2 account for about 25 percent of schools in the overall primary school population-equivalent to what we have categorized now as closed schools in the sample.

\section{Figure 14: Functionality status of schools}

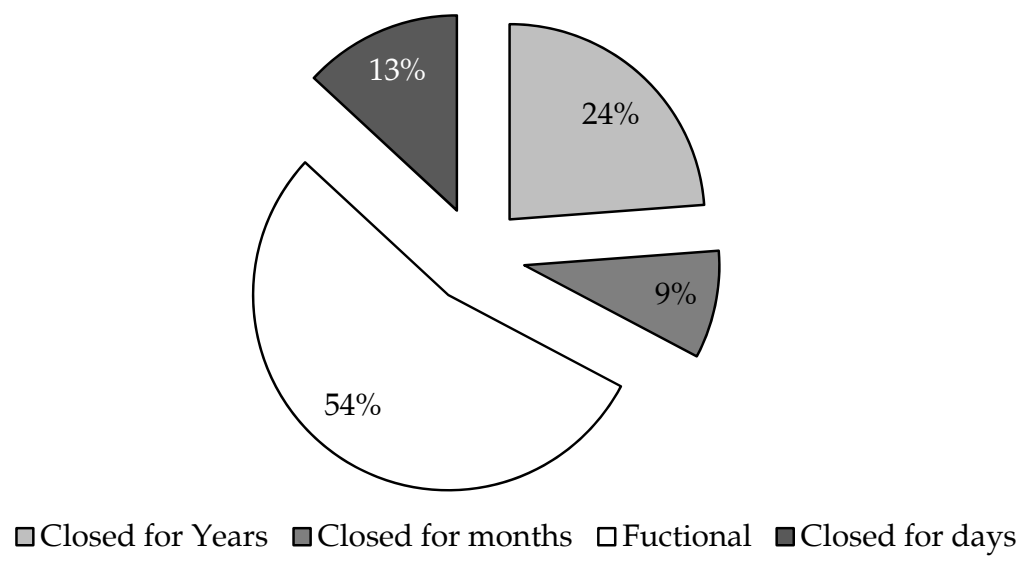

In these 300 villages, about 1,456 settlements have at least one primary school. Functional primary schools, however, are located in only 945 of these settlements. Settlements with access to functional primary schools in all districts have a higher school participation rate (ages 5-16) than settlements with no functional school (see Figure 15). The magnitude of difference, however, is small as was established in Section 2. That said, we recommend a careful analysis of disadvantaged settlements to provide low-cost schooling options in areas that lack functional government primary schools within a one-kilometer radius of the community. 
Figure 15: Participation rates and access to functional schools

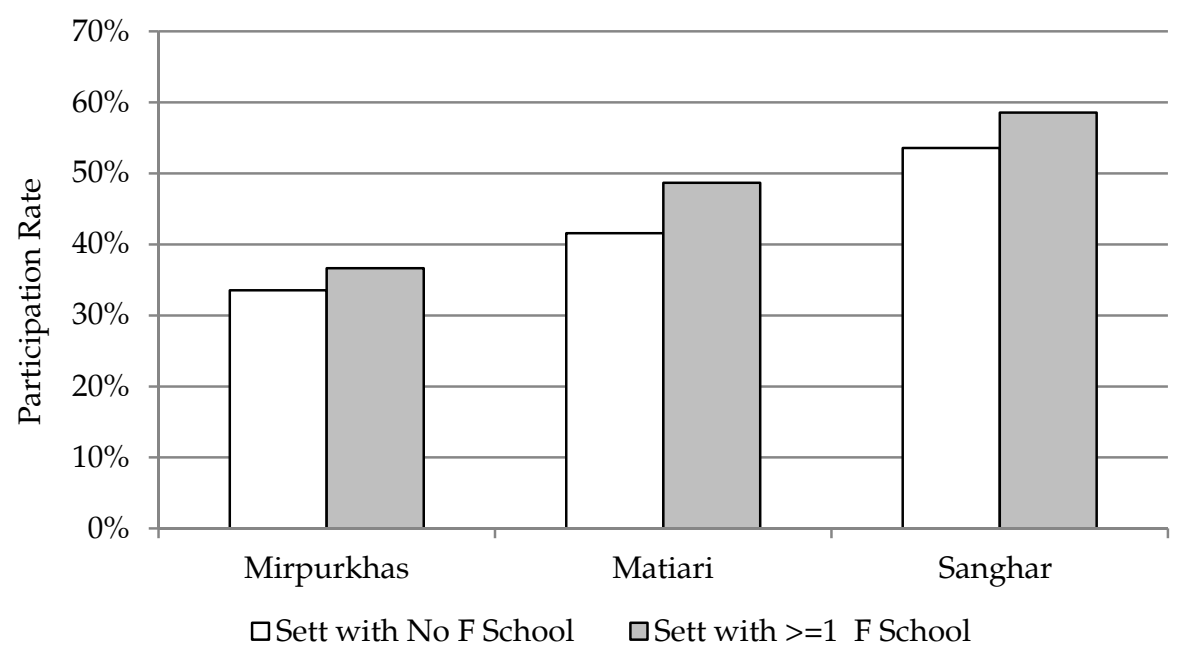

Overall, in the last six years, Sindh's performance in basic education indicators has remained wanting. At best, there have been modest improvements in primary, middle, and secondary school NERs, and only a handful of districts have demonstrated a substantial improvement in their NER. These gains could not, however, be confirmed using independently collected primary data. The robustness checks performed substantiate the body of evidence against "feedy" schools in Sindh: 24 percent of schools in 300 randomly selected villages were found to have been closed for more than a year; another 21 percent were closed on the day they were visited, and many of these had been closed for months.

\section{Conclusion}

An education policy aimed at improving governance, strengthening systems, and improving education outcomes in Sindh should be fully cognizant of the "feedy school" problem in the system, and its uncanny ability to render futile any attempts to reform education service delivery in the province. Consolidating the schooling system by absorbing these schools into functional schools could potentially lead to significant efficiency gains in the education sector. A school consolidation policy backed by teacher rationalization and the intent to depoliticize teacher placement is necessary and sufficient to ensure that school inputs are deployed where they are needed most. The Sindh government is already moving in this direction with teacher management and school consolidation identified as key reform areas in the second Sindh Education Sector Reform Program currently under implementation. 
In an education system characterized by vested interests, power, and politics, one cannot underscore enough the need to clearly separate out the results metric that quantifies progress on outcomes and system indicators to actively reduce the size of distortions in the system as a policy objective. Well-intentioned reforms are almost always comprehensive and contribute as much to the expansion of a "bad system" as they do to support "needy" schools and beneficiaries. The net effect on education outcomes is, however, zero. One example is the universal stipends program for secondary school girls in Sindh: the nontargeted nature of the program seems, at first glance, quite innocuous, but it has resulted in massive systemic inefficiencies, fattening "feedy" schools in the process.

While quantifying the results of interventions, we should not only look at the benefits to those in the "good" system, but also weigh these against the rents created for those in the "bad" system. The merit- and needs-based recruitment and placement of teachers under the Sindh Education Sector Reform Program is one such example where only the good system benefits from the intervention. Any policy that cannot make a strong case for disproportionately benefiting the good system while penalizing the bad system is not justified in a challenging political economy context such as that of Sindh.

The simple act of carving out four additional districts in 2004 significantly reduced the administrative burden of education officials, resulting in improved education outcomes in the constituent districts. This lesson resonates well with the idea of excluding closed schools from the system and reducing the court cases, inquiries, and unnecessary administrative burden that overwhelm the district management daily and reduce the time and energy they could otherwise spend on improving the system's performance. Free and compulsory education cannot be provided to all school-age children in the province simply by legislating a bill, but there is no doubt it can easily be done by acting on this body of evidence. 


\section{References}

Asim, S., \& Adil, M. (2013). Measurement of student learning: Key challenges and lessons. Unpublished manuscript.

Asim, S., Raju, D., Adil, M., Pandey, P., \& De Icaza, L. (2012). Impact of information awareness and community engagement campaign on school outcomes in Sindh, Pakistan: Baseline survey [Unpublished data].

Barrera-Osorio, F., \& Raju, D. (2012). The impacts of differential changes in benefit levels on female enrollment: Evidence from a gender-targeted CCT program in Pakistan. Unpublished manuscript.

Barrera-Osorio, F., Blakeslee, D. S., Hoover, M., Linden, L. L., \& Raju, D. (2011, June). Expanding educational opportunities in remote parts of the world: Evidence from an RCT of a public-private partnership in Pakistan. Paper presented at the Third IZA Workshop, Institute for the Study of Labor, Mexico City, Mexico.

Cheema, A., \& Mohmand, K. S. (2006, February). Bringing electoral politics to the doorstep: Who gains, who loses? Paper presented at the Decentralization Task Force Meeting of the Initiative for Policy Dialogue, Columbia University, NY.

Education statistics: Total number of schools (per capita) (most recent) by state. (2013). Retrieved from http://www.statemaster.com/red/graph/ edu_ele_sec_tot_num_of_sch_percap-total-number-schools-percapita\&b_map $=1 \&$ b_printable $=1$

Gazdar, H. (2000). State, community and universal education: A political economy of public schooling in rural Pakistan (Mimeo). London, UK: Asia Research Centre.

Horn, R. S. (2009). Quality enhancement review panel report, Pakistan: Punjab education development program and Sindh education sector reform project. Unpublished manuscript.

Keefer, P., Narayan, A., \& Vishwanath, T. (2003). The political economy of decentralization in Pakistan. In D. Mookherjee \& P. Bardhan (Eds.), Decentralization and local governance in developing countries: A comparative perspective. Cambridge, MA: MIT Press. 
World Bank. (2009). Project appraisal document: Sindh education sector project (Report No: 47642-PK). Washington, DC: Author.

World Bank. (2012a). Implementation completion and results report: Punjab education sector project (Report No: ICR2432). Washington, DC: World Bank.

World Bank. (2012b). Implementation completion and results report: Sindh education sector project (Report No: ICR2481). Washington, DC: Author.

World Bank. (2013). Project appraisal document: Second Sindh education sector project (Report No: 74552-PK). Washington, DC: Author. 